\section{SOI: 1.1/TAS DOI: 10.15863/TAS International Scientific Journal Theoretical \& Applied Science}

\author{
p-ISSN: 2308-4944 (print) e-ISSN: 2409-0085 (online) \\ Year: $2015 \quad$ Issue: $11 \quad$ Volume: 31
}

Published: $30.11 .2015 \quad$ http://T-Science.org

SECTION 31. Economic researches, finance, innovations, risk management.

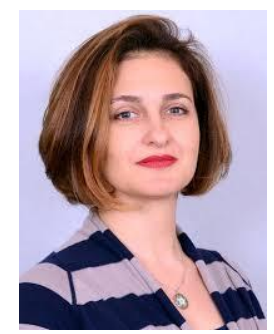

Eleonora Zabarna

Doctor of Economic Sciences,

Professor,

Odessa National Polytechnic University, Ukraine eleonoraZ@ukr.net

Anna Smorodinova Graduate student, Odessa National Polytechnic University, Ukraine

\title{
MECHANISM OF STRATEGIC INNOVATIVE DEVELOPMENT OF A REGION
}

Abstract: Article is devoted to research of mechanisms of strategic innovative development of the region. It is allocated components of the mechanism of regional innovative development. Recommendations about an occasion of activization of regional innovative policy are provided.

Key words: innovations, innovative development, strategic, mechanism, region.

Language: Russian

Citation: Zabarna EM, Smorodinova AS (2015) MECHANISM OF STRATEGIC INNOVATIVE DEVELOPMENT OF A REGION. ISJ Theoretical \& Applied Science 11 (31): 171-174.

Soi: http://s-o-i.org/1.1/TAS-11-31-27 Doi: crossef http://dx.doi.org/10.15863/TAS.2015.11.31.27

\section{МЕХАНИЗМ СТРАТЕГИЧЕСКОГО ИННОВАЦИОННОГО РАЗВИТИЯ РЕГИОНА}

Аннотация: Статья посвящена исследованию механизмов стратегического инновационного развития региона. Выделены составляющие механизма регіонального инновационного развития. Предоставлены рекомендаиии по поводу активизачии региональной инновачионной политики.

Ключевые слова: инновачии, инновационное развитие, стратегический, механизм, регион.

\section{Актуальность}

В условиях стратегической направленности Украины на инновационный тип развития, адаптация субъектов ведения хозяйства к новым условиям рыночной экономики и ее активное реформирование тесно связаны с инновациями как движущей силой экономического роста.

Расширенное воссоздание инновационного процесса во всех сферах многогранной деятельности предприятия, рациональное привлечение инновационного потенциала с целью обеспечения конкурентоспособности требует формирования механизма стратегического инновационного развития, использование которого в противовес стихийному интуитивному поиску направлений инновационного развития позволит не только повысить результативность инновационной деятельности, но и предоставит мощные возможности для повышения эффективности функционирования предприятий в условиях нестабильной экономической среды.

Исследованию механизма стратегического инновационного развития экономики Украины и еe регионов в последние годы уделяется достаточно внимания, чему и посвящены работы Амоши А., Нижнего М., Кузнецовой А., Комелиной О., Крупки М., Лапко О., Федуловой Л. и др. Направления исследований касаются отдельных составляющих механизма, но не в полной мере раскрывается вопрос стратегической составляющей механизма инновационного развития.

Целью данной статьи стало определение основных составляющих механизма стратегического инновационного развития региона.

\section{Изложение основного материала}

Эффективность инновационной деятельности в регионе зависит от сформированной системы механизмов ее инновационного развития, которые представляют собой взаимосвязь организационного, экономического и финансового механизма, который в целом определяет эффективную региональную стратегию инновационного развития и обеспечивает адаптацию инноваций к рыночным условиям [2]. Можно утверждать, что механизм инновационного развития региона 
включает в себя организационные, экономические и финансовые подходы, методы и принципы формирования региональной инновационной политики и стратегии, которые обеспечивают рост конкурентоспособности, уровня социально-экономического развития и качества жизни населения региона.

На основании проведенных теоретических исследований можно выделить основные составляющие механизма инновационного развития региона, которые включают организационные (организация, разработка и внедрение инноваций в регионе), экономические (управление, планирование и сбыт инноваций в регионе) и финансовые компоненты (финансирование и стимулирование, страхование инноваций), что позволяет определить эффективную стратегию инновационного развития региона и обеспечивает адаптацию инноваций к рыночным условиям.

Организационная составляющая должна обеспечивать появление инноваций, финансовая создать условия для финансирования инновационной деятельности, а экономическая должна обеспечить процесс коммерциализации инноваций і их дальнейшее развитие. Все виды механизма инновационного развития взаимозависимые между собой и позволяют обеспечить эффективный инновационный процесс в регионе.

Кроме того, механизм инновационного развития должен основываться на взаимодействии субъектов ведения хозяйства, государственных правительственных структур и органов местного самоуправления, в распоряжении которых находятся финансовые, материальные, минерально-сырьевые, интеллектуальные и информационные ресурсы для эффективной инновационной деятельности в регионе. При этом, все субъекты инновационной деятельности должны иметь определенную степень свободы с сочетанием высокого уровня ответственности в рамках определенных региональных приоритетов развития. Эффективность функционирования механизма инновационного развития региона зависит от обоснованного выбора инновационных проектов в соответствии с региональными приоритетами, наличию источников их финансирования, получения оптимальных эффектов от их реализации [3].

Действенный механизм инновационного развития региона начинается с эффективных организационных шагов, которые являются основой организационного механизма. Прежде всего, это касается создания и поддержки условий для инновационного развития в регионе путем:
- содействия внедрению инновационных технологий и выпуску инновационных продуктов на предприятиях региона;

- формирование трансфера технологий;

- реализация региональных программ подготовки и переподготовки кадров;

- содействие внедрению инновационных проектов предприятиями региона для потребностей коммунального хозяйства;

- обеспечение экономической безопасности субъектов инновационной деятельности региона;

- содействие организации и проведению семинаров и конференций по инновационным и научно-техническим вопросам;

- проведение мониторинга инновационной деятельности в регионе;

- усовершенствование тарифной политики для предприятий и организаций региона, которые осуществляют инновационную деятельность;

- сопровождение и контроль больших инновационных проектов на уровне региона.

Взаимодействие органов государственной и местной власти, субъектов ведения хозяйства региона при формировании инновационной политики допускает координацию деятельности всех органов власти, региональных центров по вопросам экономики, промышленной политики, инновационной и инвестиционной политики, научно-технического развития, а также совместная работа с общественными организациями, отраслевыми профсоюзами и тому подобное.

Информационная поддержка инновационного развития в регионе обеспечивается путем создания информационной инфраструктуры, которая обеспечивает распространение информации об инновационных продуктах, проектах в регионе, а также об имеющихся источниках финансирования.

Экономическая составляющая механизма развития региона отвечает за стратегическое управление инновационным развитием региона и связана с разработкой целей, программ, проектов c учетом текущего социально-экономического состояния региона, государственной политики развития инноваций, инновационного и производственного потенциала региона, внешних и внутренних факторов и потребностей региона в инновациях. Стратегия инновационного развития направлена на объединение научно-технического потенциала региона и инвестиционной политики, с помощью которой создаются инновационные продукты и технологии.

Планирование инновационного развития на сегодня осуществляется путем формирования долгосрочных программ инновационного развития региона, которые являются неотьемлемой частью программы социальноэкономического развития региона и программы 
инновационного развития Украины в целом, и содержат в себе совокупность путей, правил, процессов и инструментов, направленных на достижение поставленных стратегических инновационных и социально-экономических целей региона и Украины.

На формирование инновационноблагоприятной среды на предприятии влияют механизмы государственного регулирования и стимулирования инновационной деятельности, которые на уровне предприятия рассматриваются как внешние факторы посредственного действия. Механизмы регулирования и стимулирования инновационной деятельности формируют принципы инновационного развития конкретного предприятия на основе приведения в соответствие его внутренних возможностей развития к внешним, которые генерируются рынком. В частности, они включают:

- механизмы, которые определяют вектор формирования благоприятной среды для инновационного развития предприятия, управление изменениями опережающего развития;

механизмы, которые формируют принципы инновационно-благоприятной среды, организация инновационной деятельности, формирование инновационной культуры, мотивация персонала;

- механизмы, которые формируют ресурсную составляющую инновационноблагоприятной среды.

Именно от качественного менеджмента инновационного развития на региональном уровне зависит эффективность социального, экономического развития территории, бизнесклимат, повышение показателей качества жизни населения не только отдельного региона, но и государства в целом. Управление инновациями на любом уровне - глобальном (общегосударственном), региональном или локальном (отдельные предприятия) - это управление нестандартными процессами, ход которых можно прогнозировать лишь на основе глубоких научных исследований. Для того, чтобы предотвратить уничтожение научно-технического потенциала, государство должно существенно поддерживать научные исследования, притом настолько, чтобы обеспечить выполнение наукой eе экономической функции как главного источника инновационного пути развития социально ориентированного общества. Для улучшения ситуации важное место в направлении формирования общенациональной инновационной системы должно принадлежать разработке результативной системы внедрения механизмов стратегического инновационного развития в регионе.

\section{Выводы}

Эффективность функцонирования механизма инновационного развития региона зависит от обоснованного выбора инновационных проектов в соответствии с региональными приоритетами, наличия источников их финансирования, получения оптимальных эффектов от их реализации. Индикаторами успеха государственной инновационной политики должен стать уровень конкурентоспособности Украины и ее регионов, роста региональных внутренних продуктов и внутреннего валового продукта Украины на душу населения, их наукоемкость за счет всех источников финансирования. Проблема обеспечения конкурентоспособности национальной экономики на основе внедрения инноваций по большей части регионального характера. Каждый регион отличается своими конкурентными преимуществами и специфическими ресурсами, которые необходимо задействовать в наилучший способ при переходе к инновационному типу развития Украины. Государство должно учитывать конкурентные преимущества и специфические ресурсы разных регионов, способствовать формированию их самодостаточности и конкурентоспособности.

\section{References:}

1. (2002) Zakon Ukrainy «Pro innovatsiinu diialnist» [Tekst]: Zakon Ukrainy vid 04.07.2002 r. //Vidomosti Verkhovnoi Rady Ukrainy. - 2002. — № 36.

2. Dolishnii M (2004) Orhanizatsiinoekonomichni napriamky aktyvizatsii innovatsiinoi diialnosti v Ukraini: rehionalni aspekty [Tekst] / M. Dolishnii // Rehionalna ekonomika. - 2004. —№1. - pp. 48-54.

3. Budkin V (2010) Innovatsiina model rozvytku natsionalnykh ekonomik [Tekst] / V. Budkin//Ekonomika Ukrainy. — 2010 — № 6. — pp. 67-78. 


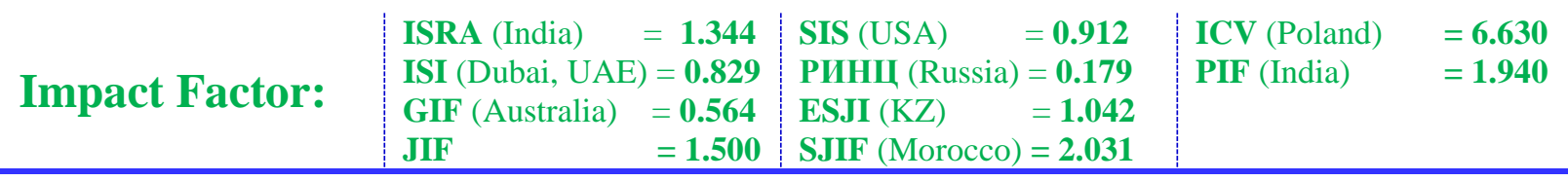

4. Honcharenko MF (2011) Mekhanizm rehuliuvannia investytsiino-innovatsiinoho rozvytku rehionu [Tekst]: avtoreferat dys. k.e.n. 08.00.05 / M.F. Honcharenko. — Chernyhiv: Chernihivskyi derzhavnyi tekhnolohichnyi universytet, 2011. - $17 \mathrm{p}$.

5. Pavlenko IA (2007) Innovatsiine pidpryiemnytstvo $\mathrm{u}$ transformatsiinii ekonomitsi Ukrainy: monohrafiia / I.A. Pavlenko. - K.: KNEU, 2007. - 248 p.

6. Santo B (1991) Ynnovatsyia kak sredstvo ekonomycheskoho razvytyia [per. s venh.] / B. Santo. - M.: Prohress, 1991. - 320 p.

7. Tkachenko VA (2008) Osnovyi konkurentnyih preimuschestv i innovatsionnogo razvitiya. Monografiya. / Pod obsch. i nauch. red. prof.
Tkachenko V.A. - D.: DUEP, Monolit, 2008. $476 \mathrm{pp}$.

8. Tkachenko VA (2007) Innovatsionnoinvestitsionnaya deyatelnost predpriyatiy promyishlennosti. Monografiya. / V.A. Tkachenko, B.I. Holod, S.I. Chimshit. - D.: DUEP, 2007. - 376 pp.

9. Fathutdinov RA (2000) Innovatsionnyiy menedzhment: uchebnik dlya vuzov / R. A. Fathtudinov. - 2-e izd. - M. : ZAO «Biznesshkola»; «Intel-Sintez», 2000. - 624 p.

10. (2014) Derzhavnyi komitet statystyky Ukrainy. Innovatsiina aktyvnist promyslovykh pidpryiemstv [Elektronnyi resurs].

Available: $\quad$ http://www.ukstat.gov.ua (Accessed: 19.03.2014).—Zahol. z ekranu. 